\title{
The bathing behavior of the chinchilla: Effects of deprivation'
}

\author{
JEFFREY J. STERN and ARIEL MERARI, University of \\ California, Berkeley, Calif. 94704
}

Four chinchilla were deprived of the sand in which they rub their fur by spinning. With increased levels of deprivation the number of spins increased and the time course of the spins was altered.

When presented with a box containing sufficient sand, a chinchilla (Chinchilla lanigera) will rub its fur in the sand by rotating around its longitudinal axis. The sand spinning behavior of the chinchilla can be divided into three phases. The first, or paw phase, is characterized by the chinchilla thrusting its front paws forward and with one or more rapid strokes drawing surface sand back towards its body. The second, or cheek phase, is characterized by the chinchilla rubbing either or both of its cheeks in the sand. The final, or spin phase, is characterized by the chinchilla partially or completely rotating around its longitudinal axis typically in the direction of its last "cheek-rub," e.g., if the chinchilla has just rubbed its right cheek in the sand, its spin (if any) will be in a clockwise direction. These three phases usually (but not necessarily) appear in the sequence outlined above.

The present study examines the effects of various periods of sand deprivation on the spinning behavior of the chinchilla.

\section{SUBJECTS}

There were four Ss, three females and one male. At the start of the experiment the females were approximately 270 days of age while the male was approximately 120 days old. Each S was housed in an individual cage with food and water available ad lib throughout the experiment. Ss were on a reversed 12-h-on/12-h-off light cycle. All testing was conducted 1-2 h prior to the dark period.

\section{PROCEDURE AND DESIGN}

All tests lasted $10 \mathrm{~min}$. E placed a clear plastic sandbox (14 $x 14 \times 4$ in.) containing approximately 2 in. of rock dust in S's home cage and recorded S's behavior. In order to examine the effects of previous as well as present deprivation, Ss were given two periods of deprivation separated by one 10 -min test. For example, in Cell 1 (Table 1) the animals were initially deprived of the sand for three days, given access to the sandbox for $10 \mathrm{~min}$, and then deprived of the sand for an additional seven days. The cell numbers refer to the sequence of deprivation periods for all animals.

\section{RESULTS AND DISCUSSION}

There does not appear to be any relation between days of sand deprivation and paw movements or between days of

Table 1

Design of the Experiment. See Text for Explanation.

\begin{tabular}{|c|c|c|c|c|c|}
\hline \multirow{6}{*}{ 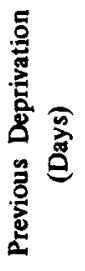 } & & \multicolumn{4}{|c|}{ Present Deprivation (Days) } \\
\hline & & 1 & 3 & 5 & 7 \\
\hline & 1 & 3 & 9 & 11 & 4 \\
\hline & 3 & 10 & 16 & 6 & 1 \\
\hline & 5 & 8 & 15 & 7 & 12 \\
\hline & 7 & 2 & 5 & 14 & 13 \\
\hline
\end{tabular}

Table 2

Percentage of Spins Occurring During each Half of the Test.

\begin{tabular}{ccc}
\hline Days of Deprivation & $\begin{array}{c}\text { Minutes } \\
1-5\end{array}$ & $\begin{array}{c}\text { Minutes } \\
6-10\end{array}$ \\
\hline 1 & 57 & 43 \\
3 & 52 & 48 \\
5 & 73 & 27 \\
7 & 80 & 20 \\
\hline
\end{tabular}

deprivation and cheek-rubs. Whether one looks at the absolute number of these movements or the ratio of the movements to spins one finds no systematic trend.

With regard to spins there are two major trends. First, as the level of deprivation was increased, the number of spins increased (Fig. 1). An analysis of variance performed on tests reveals an $\mathrm{F}$ ratio of $4.06, \mathrm{df}=3 / 48(\mathrm{p}<.025)$ for present deprivation and an $F$ ratio of $2.36, \mathrm{df}=3 / 48(\mathrm{p}<.06)$ for previous deprivation. Secondly, as the level of deprivation was increased the percentage of spins occurring during the first half of the test increased (Table 2; $\chi^{2}=23.27, \mathrm{df}=3, \mathrm{p}<.001$ ). Therefore, while the levels of sand deprivation employed in this study do not affect the number of paw movements or cheek-rubs, they do affect the number of spins and their time course. In conclusion, it is noteworthy that while the sand bathing behavior of the chinchilla serves no apparent biological need it reacts to deprivation in a manner comparable to behaviors known to serve a need, e.g., eating and drinking.

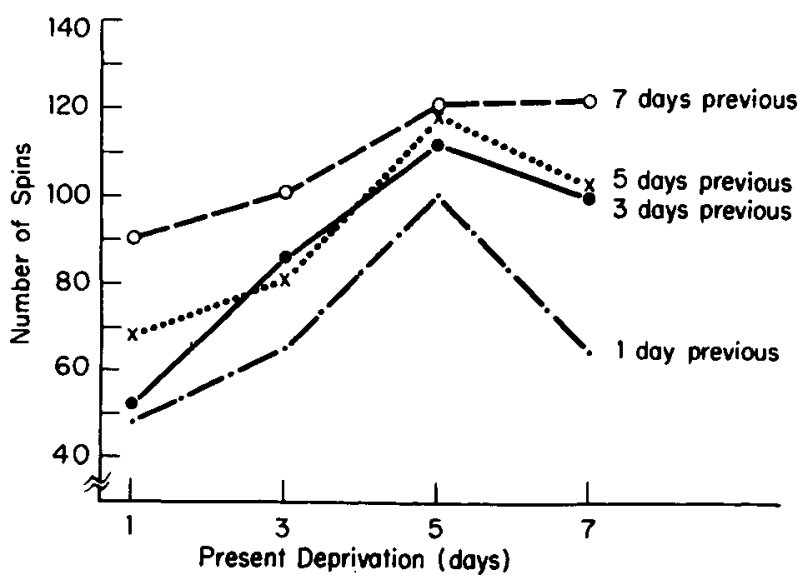

Fig. 1. Total number of spins for all Ss as a function of deprivation.

NOTE

1. This research was supported by Public Health Service Grant MH 04000 from the National Institute of Mental Health and by a grant from the Empress Chinchilla Breeders Cooperative awarded to Dr. Frank A. Beach. 